\title{
Acute impact of Hibiscus sabdariffa calyces on postprandial lipids, biomarkers of insulin resistance and inflammation in humans
}

\author{
S.M. Abubakar ${ }^{1,2}$, J.P.E. Spencer ${ }^{1}$ and J.A. Lovegrove ${ }^{1}$ \\ ${ }^{1}$ Hugh Sinclair Unit of Human Nutrition, Department of Food and Nutritional Sciences and Institute for \\ Cardiovascular and Metabolic Research, University of Reading, Reading, UK and ${ }^{2}$ Department of Biochemistry, \\ Bayero University, P.M.B. 3011, Kano, Nigeria
}

The extract of Hibiscus sabdariffa calyces (HSC) is consumed as an infusion in many countries and considered to have lipid lowering ability ${ }^{(1-3)}$, although the evidence is limited. This study aimed to investigate the acute impact of HSC extract consumption on cardiometabolic risk markers in men with 1 to $10 \%$ risk ofdeveloping cardiovascular disease (CVD) in 10 years.

A randomised, controlled, single-blinded, cross over study involving 22 men (49 \pm 2 years and BMI $\left.26 \cdot 9 \pm 0 \cdot 7 \mathrm{~kg} / \mathrm{m}^{2}\right), \mathrm{was}$ conducted in accordance with the declaration of Helsinki and Consolidated Standards of Reporting Trials (CONSORT). The study was registered as NTC02165553 ClinicalTrials.gov. Volunteers were randomised to consume either $250 \mathrm{ml}$ of the aqueous extract of HSC (containing $150 \mathrm{mg}$ anthocyanins) or water control with mixed breakfast (containing $70 \cdot 2 \mathrm{~g}$ carbohydrate, $50 \cdot 1 \mathrm{~g}$ fat and $8.6 \mathrm{~g}$ protein), followed by a lunch (containing $70.1 \mathrm{~g}$ carbohydrate, $24.9 \mathrm{~g}$ fat and $12.8 \mathrm{~g}$ protein) at 2 hours on two separate occasions separated by 2 weeks. Blood samples were collected at $0,30,60,90,120,150,180,210$ and 240 minutes post consumption of the extract of HSC or water. Postprandial glucose, insulin, triacylglycerol (TAG), total antioxidant capacity (TAC) and C-reactive protein ultra sensitive (CRP-US) responses were determined.

(a)

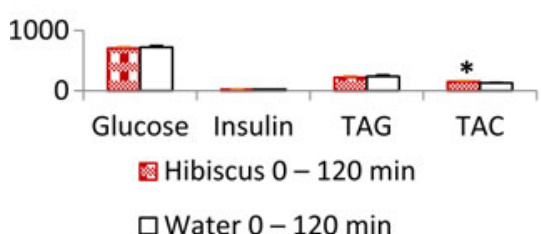

(b)

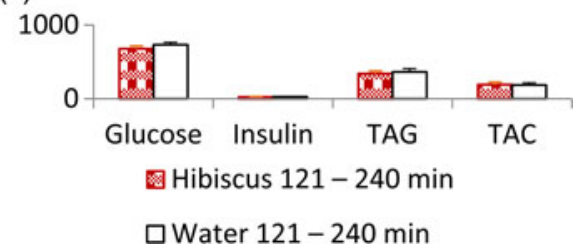

Fig. 1. Area under glucose (mmol/L*min.), insulin (nmol/L*min), TAG (mmol/L*min) and TAC (mmol Trolox Eq./L*min) response curves for $0-120$ minutes (a) and 121-240 minutes (b).

There was significant increase $(\mathrm{p}=0.026)$ in the area under 0 to 120 minutes TAC response curve when hibiscus drink consumption was compared to water (1). Although there was a tendency towards a reduced serum glucose, plasma insulin, serum TAG and CRP-US levels following acute consumption of the extract of HSC, these changes did not reach statistical significance ( $\mathrm{p}>0 \cdot 05$ ).

Acute consumption of HSC extract (containing $150 \mathrm{mg}$ anthocyanins) improved postprandial systemic antioxidant response, but did not affect postprandial glycaemic, lipidaemic or inflammatory responses.

1. Aziz Z, Wong SY \& Chong NJ (2013) J Ethnopharmacol 150, 442-450.

2. Da-Costa-Rocha I, Bonlaender B, Sievers H et al. (2014) Food Chem 165, 424-443.

3. Hopkins AL, Lamm MG, Funk JL et al. (2013) Fitoterap 85, 84-94. 